Dikirim: 2 Juli 2015 Diterbitkan: 1 Maret 2016

\section{Kepemimpinan transformasional, budaya dan komitmen organisasi di Kementerian Kesehatan}

Transformational leadership, organizational culture and commitment in the Ministry of Health

Esrika Lamashinta ${ }^{1}$, Noor Siti Rahmani ${ }^{2}$, Yayi Suryo Prabandari ${ }^{3}$

\begin{abstract}
Purpose: This study aimed to analyze the relationship of organizational culture on organizational commitment and transformational leadership that would affect performance. Methods: This study was conducted using a survey including 137 civil servants, from four units which were finance; programs and information; law, organization and public relations; and public and staffing. Results: There was a correlation between the variables of transformational leadership and organizational culture and organizational commitment of $26 \%$. Organizational culture variables had the a stronger influence on changes in the value of organizational commitment than transformational leadership. Interviews showed leadership and organizational culture had been influential and running but not all went well mostly because of routine. Conclusion: Transformational leadership and organizational culture were inseparable and mutually supportive in influencing the level of commitment of the organization's employees within the organization.
\end{abstract}

Keywords: transformational leadership; organizational culture; organizational commitment

\footnotetext{
${ }^{1}$ Kementerian Kesehatan (Email: lismasinta@gmail.com)

${ }^{2}$ Fakultas Psikologi, Universitas Gadjah Mada

${ }^{3}$ Departemen Perilaku Kesehatan, Lingkungan, dan Kedokteran Sosial, Fakultas Kedokteran, Universitas Gadjah Mada
} 


\section{PENDAHULUAN}

Menteri Kesehatan mendukung upaya pemerintah dalam reformasi birokrasi dengan Peraturan Nomor 1144/Menkes/Per/III/2010 tentang organisasi dan tata kerja kementerian kesehatan agar dapat mendorong organisasi mencapai kinerja optimal (2). Sekretariat Direktorat Jenderal Bina Upaya Kesehatan bertugas melaksanakan pelayanan teknis administrasi kepada semua unsur di lingkungan Kementerian Kesehatan.

Komitmen organisasi merujuk pada sejauh mana individu memihak pada organisasi tertentu beserta visi misinya, dan berniat mempertahankan keanggotaan dalam organisasi tersebut (3). Penerapan budaya kerja tetap harus dilaksanakan mengingat dalam organisasi sangat birokratis, terdapat kecenderungan pola budaya kerja seragam, sehingga kurang memberikan ruang gerak kreativitas dan dinamika organisasi sesuai tantangan lingkungan (4). Pada organisasi pemerintah, kesuksesan pelaksanaan tugas dan penyelenggaraan dikaitkan dengan kepemimpinan (5). Penyelenggaraan tata pemerintah yang baik (good governance) dapat terwujud jika didukung kepemimpinan dan kapasitas organisasi pemerintahan yang memadai.

Kinerja pemerintah tidak dapat dilepaskan dari pengelolaan sumber daya manusia yang efektif di setiap unit organisasi pemerintah (6), termasuk Kementerian Kesehatan yang mengemban sebagian tugas pemerintah di bidang Kesehatan. Kinerja seseorang dan organisasi juga sangat bergantung pada kemampuan manajerial pimpinan (7). Kemampuan manajerial tersebut meliputi pembangunan sistem kerja dan hubungan industrial yang aman dan harmonis, pengembangan kompetensi pekerja, dan kemampuan menumbuhkan motivasi dan mobilisasi seluruh karyawan untuk bekerja optimal.

Keberhasilan tugas Sekretariat Direktorat Jenderal Bina Upaya Kesehatan membutuhkan komitmen organisasi yang didukung kemampuan dan motivasi kerja seluruh pegawai dan diperlukan peranan pemimpin untuk dapat membina, mengembangkan organisasi, serta meningkatkan kemampuan kerja yang dimiliki pegawai dalam rangka peningkatan kinerja pegawai. Penelitian ini bertujuan untuk mengevaluasi hubungan kepemimpinan transformasional, budaya organisasi terhadap komitmen organisasi dan pegawai di Sekretariat Direktorat Jenderal Bina Upaya Kesehatan. Penelitian dilakukan dengan tujuan untuk mengetahui dan menganalisis hubungan budaya organisasi dengan kepemimpinan transformasional, komitmen organisasi yang memengaruhi kinerja di Sekretariat Direktorat Jenderal Bina Upaya Kesehatan.

\section{METODE}

Penelitian menggunakan analisis korelasi dengan pendekatan cross sectional. Penelitian ini dilaksanakan pada empat bagian yang merupakan unit kerja di lingkungan Sekretariat Direktorat Jenderal Bina Upaya Kesehatan, 1) Bagian euangan; 2) Bagian Program dan Informasi; 3) Bagian Hukum, Organisasi dan Humas; 4) Bagian Umum dan Kepegawaian, pada November 2014 sampai Desember tahun 2014.

Sampel adalah seluruh pegawai negeri sipil di lingkungan Sekretariat Direktorat Jenderal Bina Upaya Kesehatan, Kementerian Kesehatan dengan pembagian sebagai berikut: Kepala bagian sebanyak empat orang (setiap bagian diwakili satu orang), Kepala subbagian sebanyak dua belas orang (setiap bagian diwakili 3 orang), seluruh staf pelaksana teknis dan administrasi. Besar sampel dihitung menggunakan rumus Slovin.

Variabel dependen adalah komitmen organisasi, sedangkan variabel independen adalah kepemimpinan transformasional dan budaya organisasi. Penelitian dilakukan menggunakan data sekunder, primer dan kuesioner. Kuesioner dibagi menjadi 2 bagian dengan pertanyaan terbuka dan tertutup, modifikasi dari kuesioner Organizational Commitment Questionnaire (OCQ) dan Multifactor Leadership Questionnaire (MLQ). Skala pengukuran yang digunakan adalah skala Likert. Analisis menggunakan metode wawancara mendalam, untuk mendukung data kuantitatif dan mengetahui hubungan antara kepemimpinan transformasional dan budaya organisasi dengan komitmen organisasi. Wawancara mendalam terhadap 11 orang informan yang terdiri atas empat subbagian hukum, tiga subbagian organisasi, 1 subbagian humas, 2 subbagian verifikasi dan 1 dari subbagian data dan informasi. Analisis data menggunakan statistik deskriptif untuk melihat karakteristik responden dan analisis regresi linear.

\section{HASIL}

Penelitian ini dilakukan di Sekretariat Direktorat Jenderal Bina Upaya Kesehatan, merupakan unit eselon dua di bawah unit eselon satu Direktorat Jenderal Bina Upaya Kesehatan. Sekretariat Direktorat Bina Upaya Kesehatan mempunyai tugas melaksanakan pelayanan teknis administrasi kepada semua unsur di lingkungan Direktorat Jenderal Bina Upaya Kesehatan.

Sekretariat Direktorat Jenderal Bina Upaya Kesehatan menyelenggarakan fungsi, 1) koordinasi dan penyusunan rencana, program dan anggaran; 2) pengelolaan data dan informasi; 3) penyiapan urusan 
hukum, penataan organisasi, jabatan fungsional dan hubungan masyarakat; 4) pengelolaan urusan keuangan; 5) pelaksanaan urusan kepegawaian, tata persuratan, kearsipan, gaji, rumah tangga, dan perlengkapan; dan 6) evaluasi dan penyusunan laporan.

Gambar 1 menjelaskan Sekretariat Direktorat Jenderal Bina Upaya Kesehatan dibagi menjadi 4 bagian eselon 3, 1) Bagian Program dan Informasi; 2) Bagian Hukum, Organisasi dan Humas; 3) Bagian Keuangan dan 4) Bagian Kepegawaian dan Umum. Tugas dan fungsi dari masing-masing bagian berbeda namun sama-sama mempunyai tugas melaksanakan pelayanan administrasi kepada semua unsur di lingkungan Direktorat Jenderal Bina Upaya Kesehatan.

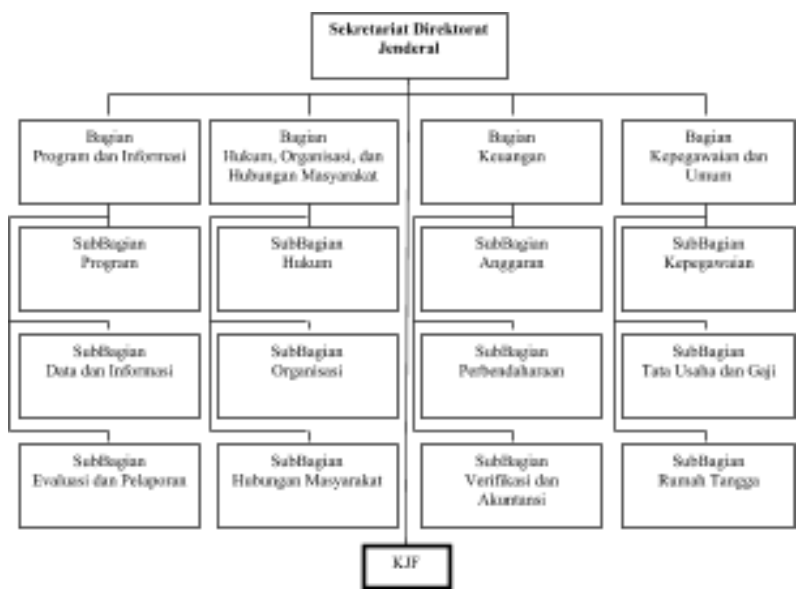

Sumber:

Peraturan Menteri Kesehatan 1144/Menkes/PER/VIII/2010

Gambar 1. Struktur organisasi Sekretariat Direktorat Jenderal Bina Upaya Kesehatan

Tabel 1 menunjukkan mayoritas pegawai di lingkungan Sekretariat Direktorat Jenderal Bina Upaya Kesehatan Kementerian Kesehatan berada pada kelompok usia 25-30 tahun, sedangkan jenis kelamin pegawai lebih banyak laki-laki dibanding perempuan. Sebagian responden memiliki tingkat pendidikan S1, dengan hampir 50\% dari seluruh pegawai yang ada di Sekretariat Direktorat Jenderal Bina Upaya Kesehatan Kementerian Kesehatan berada pada level S1. Masa kerja paling dominan dari seluruh pegawai adalah kurang dari 5 tahun dan dari 12 unit kerja,, terbanyak adalah pada subbagian Tata usaha (TU) dan gaji.
Tabel 1. Ciri responden $(n=11)$

\begin{tabular}{lc}
\hline Variabel & $\%$ \\
\hline Usia & \\
25-30 tahun & 26,3 \\
31-35 tahun & 23,3 \\
36-40 tahun & 12,4 \\
41-45 tahun & 6,6 \\
46-50 tahun & 9,5 \\
51-55 tahun & 16,8 \\
56-60 tahun & 5,1 \\
Jenis kelamin & \\
Laki-laki & 48,9 \\
Perempuan & 51,1 \\
Pendidikan & \\
< SLTA & 3,6 \\
SLTA & 19,0 \\
D III & 16,1 \\
S1 & 48,9 \\
S2 & 12,4 \\
Masa kerja & \\
< tahun & 34,3 \\
6-10 tahun & 28,5 \\
11-15 tahun & 3,6 \\
16-20 tahun & 3,6 \\
21-25 tahun & 19,7 \\
26-30 tahun & 10,3 \\
Unit kerja & \\
Subbag program & 10,2 \\
Subbag datin & 10,9 \\
Subbag evapor & 2,2 \\
Subbag hukum & 10,2 \\
Subbag organisasi & 8,0 \\
Subbag humas & 6,6 \\
Subbag perbendaharaan & 6,6 \\
Subbag anggaran & 8,0 \\
Subbag verifikasi & 10,2 \\
Subbag kepegawaian & 6,6 \\
Subbag TU dan gaji & 13,9 \\
Subbag rumah tangga & 6,6 \\
\hline & \\
&
\end{tabular}

Tabel 2 menyebut bahwa rata-rata skor komitmen organisasi pegawai adalah 51,32 dengan standar deviasi 4,58, sedangkan skor terendah untuk komitmen organisasi adalah 42 dan skor tertinggi 62. Rata-rata skor kepemimpinan transformasional 63,62 dengan standar deviasi 10,30 dan skor terendah 21 dan tertinggi 90. Untuk rata-rata skor budaya organisasi 57,29 standar deviasi adalah sebesar 6,72 dan nilai terendah 40 dan tertinggi 80.

Tabel 2. Karakteristik variabel penelitian

\begin{tabular}{|c|c|c|c|c|}
\hline \multirow{2}{*}{ Variabel } & \multicolumn{4}{|c|}{ Ukuran Tendensi } \\
\hline & $\mathbf{n}$ & Mean \pm SD & Min & $\operatorname{Max}$ \\
\hline $\begin{array}{l}\text { Komitmen } \\
\text { organisasi pegawai }\end{array}$ & 137 & $51,32 \pm 4,58$ & 42 & 62 \\
\hline $\begin{array}{l}\text { Kepemimpinan } \\
\text { transformasional }\end{array}$ & 137 & $\begin{array}{c}63,62 \pm \\
10,30\end{array}$ & 21 & 90 \\
\hline Budaya organisasi & 137 & $57,29 \pm 6,72$ & 40 & 80 \\
\hline
\end{tabular}




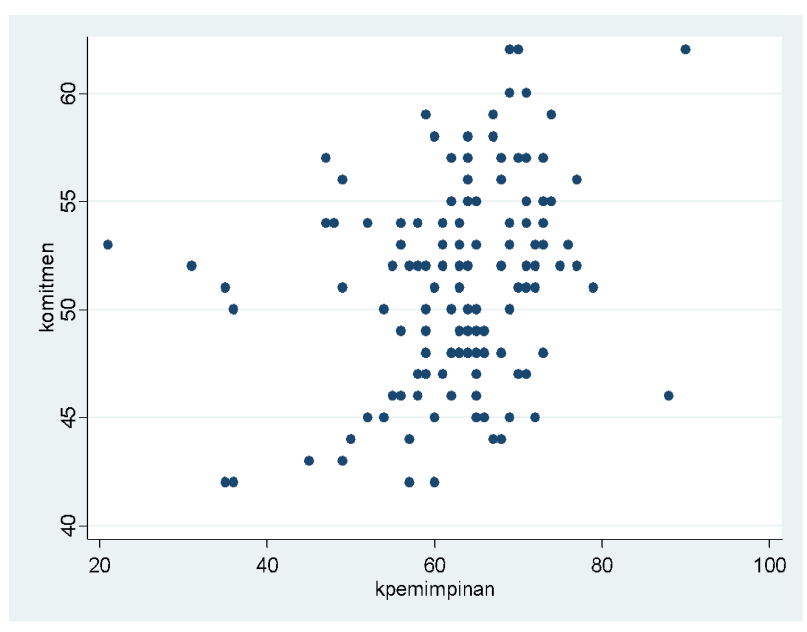

Gambar 2. Uji linearitas antara kepemimpinan transformasional dengan komitmen organisasi

Uji linearitas menjadi syarat sebelum melakukan uji regresi linear. Uji linearitas dilakukan untuk mengetahui linearitas dua variabel (hubungan prediktor sebagai variabel independen dengan kriterium sebagai variabel dependen).

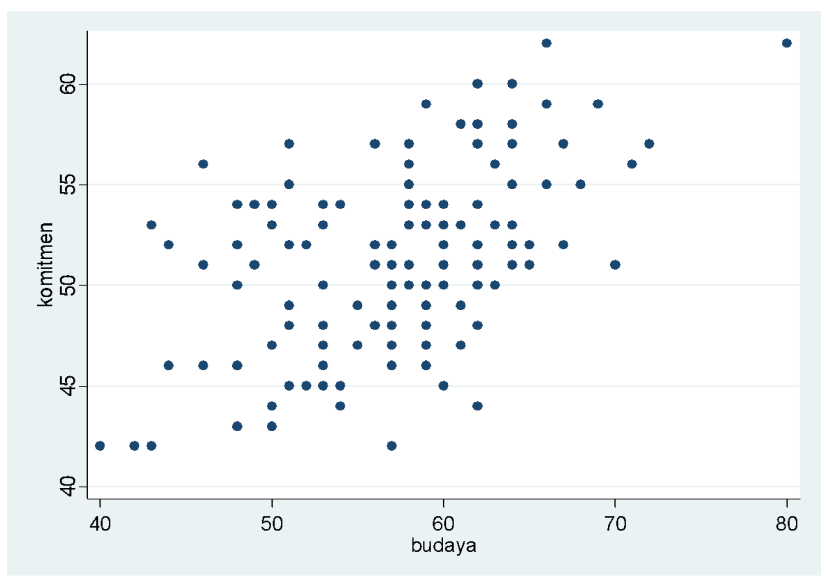

Gambar 3. Uji linearitas antara kepemimpinan transformasional dengan komitmen organisasi

Gambar 3 menjelaskan kepemimpinan dengan komitmen organisasi memberi kesan bahwa korelasi yang terjadi bersifat linear positif. Kenaikan nilai kepemimpinan meningkatkan komitmen organisasi. Korelasi antara kepemimpinan dengan komitmen dapat diuji dengan uji korelasi.

Korelasi antara kepemimpinan transformasional dengan komitmen organisasi dilihat dari arah korelasi, besarnya korelasi, dan kemaknaan. Kepemimpinan transformasional meningkat maka nilai komitmen organisasi menjadi meningkat. Besar korelasi secara statistik termasuk lemah. Nilai budaya organisasi meningkat maka nilai komitmen organisasi juga meningkat.
Tabel 3. Korelasi kepemimpinan transformasional dan budaya organisasi terhadap komitmen organisasi

\begin{tabular}{lcc}
\hline \multirow{2}{*}{ Variabel } & \multicolumn{2}{c}{ Komitmen Organisasi } \\
\cline { 2 - 3 } & $\mathbf{r}$ & P-Value \\
\hline Kepemimpinan & 0,29 & $<0.05^{*}$ \\
transformasional & & \\
Budaya organisasi & 0,50 & $<0.05^{*}$ \\
\hline *)terdapat hubungan yang bermakna &
\end{tabular}

Tabel 4. Hasil regresi linear

\begin{tabular}{lccc}
\hline \multicolumn{1}{c}{ Variabel } & $\begin{array}{c}\text { Model 1 } \\
\text { Koefisien } \\
\mathbf{9 5 \% C I} \\
\text { P-Value }\end{array}$ & $\begin{array}{c}\text { Model 2 } \\
\text { Koefisien } \\
\mathbf{9 5 \% C I} \\
\mathbf{P - V a l u e}\end{array}$ & $\begin{array}{c}\text { Model 3 } \\
\text { Koefisien } \\
\mathbf{9 5 \% C I} \\
\boldsymbol{P - V a l u e}\end{array}$ \\
\hline Kepemimpinan & 0,13 & & $-0,06$ \\
transformasional & $(0,06-0,20)$ & & $(-0,15-0,03)$ \\
& $0,000^{*}$ & & 0,201 \\
Budaya organisasi & & 0,34 & 0,41 \\
& & $(0,24-0,44)$ & $(0,26-0,55)$ \\
& & $0,00^{*}$ & $0,00^{*}$ \\
\hline Konstanta & 42,98 & 31,61 & 31,66 \\
\hline $\mathbf{R}^{2}$ & 0,08 & 0,25 & 0,26 \\
\hline $\mathbf{n}$ & 137 & 137 & 137 \\
\hline
\end{tabular}

Analisis multivariabel pada model 1 menunjukkan seberapa besar hubungan antara kepemimpinan transformasional dengan komitmen organisasi yang mempunyai hubungan yang bermakna secara statistik. Kepemimpinan transformasional dapat berkontribusi terhadap peningkatkan nilai komitmen organisasi sebesar $8 \%$. Terdapat peningkatan nilai $\mathrm{R}^{2}$ pada model 2. Budaya organisasi lebih besar dibandingkan kepemimpinan transformasional dalam berkontribusi terhadap peningkatan nilai komitmen organisasi. Model 3 memiliki nilai $\mathrm{R}^{2}$ tertinggi jika dibandingkan dengan model lain. Model 3 dipilih sebagai model terbaik untuk menggambarkan variabel yang berhubungan terhadap perubahan nilai komitmen organisasi berdasarkan nilai koefisien determinasi dan pengamatan peneliti selama penelitian berlangsung. Analisis regresi membuktikan bahwa variabel budaya organisasi memiliki pengaruh paling kuat terhadap perubahan nilai komitmen organisasi dibandingkan kepemimpinan transformasional.

"Sudah berfungsi karena pimpinan sekarang ini selalu memberikan arahan kepada staf-staf agar menjaga dan melaksanakan komitmen yang sudah dibuat oleh subbag, pimpinan memberikan dan mengajarkan hal-hal dalam menunjang pekerjaan, memberikan contoh yang baik dalam melaksanakan pekerjaan, memberikan motivasi untuk selalu bekerja dan pimpinan ikut berpartisipasi hingga ke detail pekerjaan yang dibuat oleh staf, mengawasi langsung serta menentukan putusan dalam pekerjaan” (R-11)

"Berpengaruh positif karena kinerja makin baik dan meningkatkan komitmen kerja, hanya terkadang pimpinan suka ikut campur dalam penyelesaian 
pekerjaan hingga ditungguin dan itu membuat pekerjaan kurang optimal” (R-10)

Beberapa informan mengatakan kepemimpinan tidak berfungsi secara baik.

"Sejauh pandangan saya, yang pasti kepemimpinan harus memiliki visi dan komitmen kerja, jika kita memiliki komitmen untuk menyelesaikan pekerjaan sehingga seluruh lini kebutuhan dalam bekerja dipenuhi, baik dalam hal memanaje staf, dan kebutuhan untuk staf dan untuk diselesaikan, namun saat ini tidak ada kejelasan dan arahan untuk diselesaikan atau tidak, dan tidak ada komitmen untuk menyelesaikan pekerjaan, sehingga motivasi dari masing-masing staf jadi tidak inline dengan apa yang harus dikerjakan” (R-3)

"Belum berfungsi dengan maksimal karena pekerjaan masih bersifat rutinitas setiap tahunnya sehingga atasannya siapapun kami sudah tau job desc masing-masing dan sudah tau apa yang akan dikerjakan setiap tahunnya, meningkatkan komitmen atau tidak itu datang dari dalam diri sendiri bukan karena kasubbag. Berfungsi tetap namun tidak maksimal karena tetap ada dukungan, arahan, diskusi dan lainnya untuk menyelesaikan pekerjaan, supporting tetap ada walau tidak maksimal” (R-8)

Dari wawancara dengan beberapa orang, sebagian besar menyatakan bahwa peran dalam meningkatkan komitmen organisasi di Sekretariat Direktorat Jenderal Bina Upaya Kesehatan Kementerian Kesehatan belum maksimal. Beberapa informan berpendapat bahwa kepemimpinan lebih berperan dalam memotivasi dibandingkan meningkatan komitmen organisasi,

"Belum maksimal, jika memberi support maksimal, arahan lebih jelas, capability nya lebih tinggi, lebih expert, karena atasan sebelumnya sudah lebih expert dan lebih berpengalaman bertahun-tahun sehingga kami lebih terpacu untuk bekerja. Kalau kasubbag yang sekarang masih baru masih tahap belajar, efeknya semangat kerja jadi tidak sebesar semangat dibanding atasan sebelumnya yang lebih berpengalaman” (R-8)

"Kasubbag sekarang sudah cukup memberikan motivasi dalam bekerja, namun beberapa hal kurang spesifik, arahan yang diberikan masih arahan umum, dan tidak memberikan uraian pekerjaan ke masing-masing staf, tidak membedakan staf baru dan staf lama, mengupayakan porsi kerja antar sesama staf. Menurut saya sebagai staf baru, arahan kurang jelas dalam job desc, disini saya belum ada bimbingan atau penjelasan untuk staf baru sehingga belajar sendiri secara learning by doing” (R-10)

Sekretariat Direktorat Jenderal Bina Upaya Kesehatan Kementerian Kesehatan kepemimpinan menerapkan reward dan punishment pada kedisiplinan terhadap pegawai.
"Kasubbag sekarang memiliki disiplin kerja, dan mencontohkan disiplin dalam bekerja, apabila ada staf yang tidak disiplin akan dilakukan teguran dan pembinaan, contoh pemberian izin apabila jelas akan diizinkan, dan bagi staf yang prestasi kerjanya bagus akan diberikan reward" (R-9)

"Pimpinan melakukan system reward dan punishment terhadap staf yang tidak disiplin dengan menegur, dan memberikan reward terhadap staf yang berprestasi, hanya saja teguran yang diberikan kurang tegas, apalagi terhadap staf yang bandel dan tidak disiplin hanya menegur tanpa tindakan lanjutan seperti sanksi administratif lain dan terkadang hanya didiamkan saja bagi staf staf yang tidak disiplin dan tidak mau dikoreksi” (R-11)

Budaya organisasi sudah berjalan dengan baik dan sudah sesuai dengan masing-masing subbag. Hal ini karena bersifat rutinitas dan merupakan tanggung jawab mereka.

"Sudah baik dan sudah paham pekerjaan apa yang dikerjakan karena pekerjaan rutinitas, budaya kerja di subbag ini ada atau tidak ada bos kami sudah tau apa yang harus diselesaikan, atasan hanya untuk memantau pekerjaan, menentukan prioritas mana yang urgent dan harus diselesaikan. Staf disini peduli dengan pekerjaan staf lain, sehingga apabila staf overload pekerjaan akan dibantu dengan staf lain" (R-9)

\section{BAHASAN}

Kepemimpinan transformasional berkontribusi pada peningkatkan nilai komitmen organisasi. Hasil penelitian didukung dari wawancara mendalam bahwa sudah berpengaruh positif dan sudah berfungsi saat ini, namun belum maksimal. Hasil penelitian didukung oleh pendapat bahwa gaya kepemimpinan transformasional berpengaruh secara tidak langsung terhadap komitmen organisasi yaitu melalui kepuasan kerja pegawai, yang apabila kepuasan kerja pegawai tinggi maka semakin tinggi pula komitmen organisasi (8). Kepemimpinan transformasional memengaruhi komitmen organisasi pegawai dengan menaikkan nilai intrinsik dihubungkan dengan pencapaian tujuan, menekankan usaha dari pegawai dengan pencapaian tujuan, dan menciptakan tingkat komitmen personal lebih tinggi baik pemimpin dan pegawai dengan visi, misi dan tujuan organisasi.

Penelitian di perusahaan Amerika di Malaysia Timur menunjukkan kepemimpinan transformasional mempunyai hubungan positif dan signifikan dengan komitmen organisasi (9). Ada hubungan langsung dan positif antara kepemimpinan transformasional dengan komitmen organisasi (10). 
Penelitian ini menunjukkan bahwa kepemimpinan di lingkungan Sekretariat Direktorat Jenderal Bina Upaya Kesehatan lebih banyak cenderung memotivasi pegawai. Hal ini sesuai dengan pendapat bahwa pemimpin transformasional memotivasi para stafnya dengan mengajak untuk menginternalisasi dan memprioritaskan kepentingan bersama yang lebih besar di atas kepentingan pribadi (11).

Penelitian di Turki menyimpulkan bahwa kepemim- pinan transformasional meningkatkan komitmen dan loyalitas karyawan terhadap organisasi (12). Penelitian sebelumnya menemukan bahwa perilaku pemimpin transformasional berhubungan dengan komitmen organisasional (13).

Budaya organisasi memiliki hubungan yang signifikan dengan komitmen organisasi pegawai. Hasil analisis regresi menunjukkan bahwa variabel budaya organisasi memiliki pengaruh paling kuat terhadap perubahan nilai komitmen organisasi dibandingkan kepemimpinan transformasional.

Penelitian ini didukung pendapat bahwa pengaruh budaya organisasi berpengaruh secara positif dan signifikan terhadap komitmen organisasi (14). Budaya organisasi dan gaya kepemimpinan mempunyai pengaruh yang signifikan terhadap komitmen kerja karyawan (15).

Budaya organisasi mempunyai hubungan yang signifikan dengan komitmen organisasi. Semakin baik budaya organisasi yang diterapkan, semakin tinggi komitmen organisasi yang diterapkan oleh pegawai (16). Penelitian lain menemukan pengaruh budaya organisasi dan komitmen organisasional (17). Semakin kuat budaya organisasi maka semakin tinggi komitmen organisasional dalam diri karyawan oleh sebab itu suatu organisasi perlu menerapkan nilai-nilai dan peraturan-peraturan yang akan memengaruhi perilaku karyawan yang mengarah pada terbentuk komitmen organisasional.

Penelitian memberikan gambaran kepemimpinan transformasional menaikan nilai komitmen organisasi. Kepemimpinan transformasional merupakan bagian dalam menunjang komitmen organisasi di Sekretariat Direktorat Jenderal Bina Upaya Kesehatan. Para Kepala subbagian harus memiliki kemampuan kepemimpinan transformasional dalam memimpin pegawai subbag agar komitmen organisasi pegawai dapat ditingkatkan. Kualitas pemimpin merupakan faktor terpenting yang menentukan keberhasilan atau kegagalan organisasi. Untuk menjadi pemimpin yang efektif, Kepala subbagian harus memberi contoh dan memengaruhi pegawai bagian dengan cara positif untuk mencapai tujuan subbag.

Kepala subbag harus memotivasi, memunculkan ide kreatif dan inovasi bawahan, memperlakukan setiap pegawai secara individual serta selalu melatih dan memberi pengarahan. Sekretariat Jenderal Bina Upaya Kesehatan diharapkan untuk memaksimalkan upaya dalam rangka meningkatkan kemampuan manajerial Kasubbag dan kemampuan teknis pegawai pada masing-masing subbagian agar tujuan upaya kesehatan di Kementerian Kesehatan tercapai secara optimal.

\section{SIMPULAN}

Penelitian menemukan adanya hubungan positif dan signifikan antara kepemimpinan transformasional dan budaya organisasi dengan komitmen organisasi pegawai di Sekretariat Direktorat Jenderal Bina Upaya Kesehatan. Kepemimpinan transformasional dan budaya organisasi tidak dapat dipisahkan dan saling mendukung dalam memengaruhi komitmen organisasi pegawai di lingkungan organisasi ini.

\begin{abstract}
Abstrak
Tujuan: Penelitian ini bertujuan untuk mengetahui dan menganalisis hubungan budaya organisasi dengan kepemimpinan transformasional dan komitmen organisasi yang memengaruhi kinerja. Metode: Penelitian berupa survei terhadap 137 pegawai negeri di unit: pembiayaan; program dan informasi; hukum, organisasi dan hubungan masyarakat; publik dan kepegawaian. Hasil: Terdapat hubungan antara kepemimpinan transformasional dan budaya organisasi terhadap komitmen organisasi sebesar 26\%. Budaya organisasi memiliki pengaruh paling kuat terhadap perubahan nilai komitmen organisasi dibandingkan kepemimpinan transformasional. Hasil wawancara menunjukkan kepemimpinan dan budaya organisasi sudah berpengaruh dan berjalan namun belum semua baik, hanya karena rutinitas. Simpulan: Kepemimpinan transformasional dan budaya organisasi tidak dapat dipisahkan dan saling mendukung dalam memengaruhi tinggi rendahnya komitmen organisasi pegawai di lingkungan organisasi.
\end{abstract}

Kata kunci: kepemimpinan transformasional; budaya organisasi; komitmen organisasi 


\section{PUSTAKA}

1. Sinambela LP. Reformasi Pelayanan Publik. Jakarta: Bumi Aksara; 2006.

2. Menkes RI. Peraturan Menteri Kesehatan Republik Indonesia No. 1144/Menkes/Per/III/2010 tentang organisasi dan tata kerja kementerian kesehatan. Jakarta: Kementerian Kesehatan RI; 2010.

3. Ikhsan A, Ishak M. Akuntansi Keperilakuan. Jakarta: Salemba Empat; 2005.

4. Hatch MJ, Schultz M. The dynamics of organizational identity. Human relations. 2002;55(8):989-1018.

5. Carmeli A, Freund A. Work commitment, job satisfaction, and job performance: an empirical investigation. International Journal of Organization Theory and Behavior. 2004;7(3):289-309.

6. Robbins SP. Perilaku organisasi, konsep kontroversi aplikasi. Jakarta: PT Prenhallindo; 2004.

7. Simanjuntak PJ. Manajemen dan Evaluasi Kinerja. Jakarta: Lembaga penerbit Fakultas Ekonomi Universitas Indonesia; 2005.

8. Lamidi. Pengaruh kepemimpinan transformasional terhadap komitmen organisasi dengan variabel moderating kepuasan kerja pegawai rumah sakit swasta di PKU Muhammadiyah Surakarta. Jurnal Ekonomi dan Kewirausahaan. 2009;9(1):12-22.

9. Ismail A, Mohamed H, Sulaiman AZ, Mohamad MH, Yusuf M. An empirical study of the relationship between transformational leadership, empowerment and organizational commitment. Business and Economics Research Journal. 2011;2(1):89-107.

10. Farahani M, Taghadosi M, Behboudi M. An exploration of the relationship between transformational leadership and organizational commitment: The moderating effect of emotional intelligence: Case study in Iran. International Business Research. 2011;4(4):p211.

11. Asgari A, Silong AD, Ahmad A, Samah BA. The relationship between transformational leadership behaviors, organizational justice, leader-member exchange, perceived organizational support, trust in management and organizational citizenship behaviors. European Journal of Scientific Research. 2008;23(2):227-42.

12. Tuna M, Ghazzawi I, Akbas Tuna A, Catir O. Transformational leadership and organizational commitment: The case of Turkey's hospitality industry. SAM Advanced Management Journal. 2011;76(3):10.

13. Dunn MW, Dastoor B, Sims RL. Transformational leadership and organizational commitment: A cross-cultural perspective. Journal of Multidisciplinary Research. 2012;4(1):45.

14. Sopiah. Budaya organisasi, komitmen organisasional pimpinan dan pengaruhnya terhadap kepuasan kerja dan kinerja karyawan Bank. Jurnal Keuangan dan Perbankan. 2008;12(2):3008-31.

15. Pasek IK. Budaya organisasi serta pengaruhnya terhadap kepemimpinan dan komitmen kerja karyawan. Sarathi 2008;15(1).

16. Dewi KS. Pengaruh gaya kepemimpinan transformasional terhadap kepuasan kerja karyawan dan komitmen organisasi pada PT. KPM. Jurnal Manajemen, Strategi Bisnis, dan Kewirausahaan. 2013;7(2):116-25.

17. Taurisa CM, Ratnawati I. Analisis pengaruh budaya organisasi dan kepuasan kerja terhadap komitmen organisasional dalam meningkatkan kinerja karyawan (Studi pada: PT. Sido Muncul Kaligawe Semarang. Jurnal Bisnis dan Ekonomi 2012;19(2):170-87. 
Berita Kedokteran Masyarakat, Volume 32 No. 3 Tahun 2016 